\title{
Family Physicians' Knowledge of Risk Factors for Cervical Cancer
}

\author{
MACK T. RUFFIN IV, M.D., M.P.H.
}

This study was supported by grants from the Research Council of the Department of Family Practice and Community Health at the University of Minnesota, the Bureau of Health Professions HRSA Grant for Faculty Development in Family Medicine, the Minnesota Medical Foundation, the American Academy of Family Physicians Foundation, the American Cancer Society, and the Research Committee of the Department of Family Practice at the University of Michigan. M.T.R. is supported by a grant from the National Cancer Institute (CA 80846).

\begin{abstract}
Background: A woman's risk for cervical cancer has been used by physicians to guide the initiation and frequency of a Pap smear. The aim of this study was to determine family physicians' knowledge of risk factors for cervical cancer and perceived importance of risk in screening women.

Methods: The self-administered questionnaire was mailed to 5000 randomly selected active members of the American Academy of Family Physicians (AAFP).

Results: Data from 2748 usable questionnaires indicated the mean number of risks considered for cervical cancer was 4.5. Physician's age and the number of reported risks were inversely correlated $(p=0.0001)$. Female physicians reported significantly more risk factors than male physicians $(p=0.05)$. The number of Pap smears performed per month was positively correlated with the number of risk factors reported $(p=0.001)$. Only $10 \%$ of the physicians indicated that they perform a Pap smear at the same interval regardless of the risk of the woman.

Conclusions: This sample of family physicians has a limited understanding of the risk factors for cervical cancer. This was true regardless of the age, gender, training, race, geographic location, or practice setting of the responding physician. Yet the usual practice of screening for cervical cancer reported by these physicians would suggest that knowledge and use of risk factors would be a critical aspect of screening for cervical cancer.
\end{abstract}

\section{INTRODUCTION}

I N 1941, EXFOLIATIVE CERVICAL CYTOLOGY was introduced by Papanicolaou and Traut $^{1}$ as a method for the early diagnosis of "carcinoma of the female genital tract." Since its introduction as a vaginal pool aspiration, the Pap smear has rapidly evolved through a broad spectrum of techniques and protocols, ${ }^{2-4}$ with wide acceptance by physicians. Although no definitive ran-

Department of Family Medicine, The University of Michigan Health System, Ann Arbor, Michigan. 
domized, control led trial has been done to determine efficacy of this screening procedure in reducing morbidity and mortality, a number of studies have indirectly demonstrated efficacy by reporting a decrease in the incidence of invasive cervical carcinoma associated with increased screening. ${ }^{5-11}$ Studies continue to show mass Pap smear screening to result in early detection and treatment with a marked decline in mortality rates. $^{12}$

A number of single steps within cervical cancer screening are critical to maintaining a highly efficacious screening program. The physician's role is central to the process, as emphasized by several professional organizations. ${ }^{13-15}$ As a woman's risk for cervical cancer changes, so do the recommendations for when to initiate screening and how frequently to screen. Medicare provides coverage for a Pap smear and pelvic examination once every 24 months. If a woman is at high risk for cervical or vaginal cancer, Medicare covers these tests every 12 months. The American Cancer Society (ACS) currently recommends that all women begin yearly Pap tests within 3 years of vaginal intercourse, but no later than age $21 .^{16}$ Screening should be annual until age 30 . Starting at age 30, women who have had three consecutive, technically satisfactory, normal/negative cytology tests may increase the interval to every 2-3 years. ${ }^{16}$ Previously, the ACS recommended that if a woman had three negative annual Pap tests in a row, this test could be done less often at the judgment of the woman's health care professional. ${ }^{13}$ This judgment hinges on the risk to the woman. Therefore, being able to estimate a woman's level of risk is valuable in the screening process for cervical cancer. Despite the tens of millions of Pap smears done annually, it is unknown whether physicians are able to make an accurate assessment of a woman's risk for cervical cancer.

The study objectives were to determine which risk factors for cervical cancer are considered by family physicians and what importance they attach to each risk factor in screening women. In addition, the study sought to determine family physicians' perceptions of the percentage of women in their practice at increased risk for cervical cancer. This study was conducted in 1995, when the recommendations for the interval for Pap smear screening were based on the risk to the woman.

\section{MATERIALS AND METHODS}

A self-administered questionnaire was developed and modified based on a series of pilot studies. The final questionnaire used in this study consisted of 44 closed-ended questions and 2 open-ended questions. To facilitate completion, the questionnaire was sequenced to follow the steps in collecting a Pap smear. ${ }^{17}$ The reliability was determined for each item of the questionnaire using kappa statistics for categorical data and correlation coefficients for continuous data. The reliability was excellent, with kappa statistic range .75-.90 and correlation coefficient range $.83-.90$, with all 50 physicians completing the questionnaire each time.

The format for accessing physicians' knowledge of risk factors for cervical cancer was a statement that the medical literature suggests there are as many as 10 identifiable risk factors. Ten slots were provided along with a scale next to each slot for physicians to rate the importance of the risk factor in their decision on when to start and how often to screen for cervical cancer. The scale was a 5-point scale from 1 (minimal importance) to 5 (very important). In the pilot studies of 300 physicians, the number of risk factors reported ranged from 3 to 10 evidence-supported risk factors, with only 10 risk factors that were not supported by evidence. The number of risk factors reported, the specific risk factor listed, and the importance rating of each risk factor did not change with repeated completion of the survey.

The self-administered questionnaire was mailed with a cover letter that included an introduction of the project, quotes from nationally recognized leaders in family practice supporting the study, and an envelope with return postage. The nonresponders were mailed reminders at 2 and 4 weeks after the first mailing. At 6 weeks, another survey and second cover letter were mailed to nonrespondents. This was followed by mailed reminders 2 and 4 weeks later. The final group of nonresponders was contacted by telephone to determine if the physician was still in practice and if that physician saw women and screened for cervical cancer.

The study sample was 5000 randomly selected active members of the American Academy of family physicians (AAFP). Active members are practicing physicians or full-time teachers of family practice who are graduates of a school of med- 
icine. These members are required to report 150 hours of AAFP-approved continuing medical education credits every 3 years. The total population at the time of sampling was 38,095 active members, with 33,141 men and 4,950 women.

The physicians' responses relevant to research questions were examined in terms of percent distribution and means to describe the group. Comparisons between different groups were done with appropriate chi-square, $t$ test univariate comparisons, or correlation (zero-order and partial). The variables used to determine groups for comparisons were physician's gender, residency training status, and number of Pap smears performed per month.

\section{RESULTS}

The responses to the mailed physicians' survey were 3551 (71\%) with 2748 (55\%) usable questionnaires. The reasons for excluding the 803 responses were cervical cancer screening not part of their clinical practice $(466,58 \%)$, physician no longer involved in patient care $(249,31 \%)$, and physician no longer alive $(88,11 \%)$. No difference was found between respondents (3551) and nonrespondents (1449) by age (mean age 44.8 years vs. 49.1 years) and gender (male $82.7 \%$ vs. $85.2 \%$ female). Of the 1449 nonresponders, 800 were reached by telephone. Among these 800 physicians, $384(48 \%)$ did not see women, $240(30 \%)$ did not screen for cervical cancer in their practice, $96(12 \%)$ had moved to another practice location, and $80(10 \%)$ were no longer in clinical practice. No other information was available on the nonresponders for comparison. Demographic features of the responding physicians are shown in Table 1.

The average number of Pap smears performed monthly is shown in Table 2, along with the average number of patient visits per month by gender of the provider. Male family physicians report seeing significantly more patients on average each month $(p<0.00001)$, whereas female family physicians report performing significantly more

Table 1. Demographic Features of Respondents with Usable Responses $(n=2748)$

\begin{tabular}{lcc}
\hline Feature & Men & Women \\
\hline Number (\%) & $2273(82.7)$ & $449(16.3)$ \\
Mean age, years (SD) & $45.8(11.3)$ & $39.4(8.9)$ \\
Training, number (\%) & & \\
Internship only & $555(24.5)$ & $38(8.5)$ \\
1-3 years FP residency & $322(58.5)$ & $4345(77.4)$ \\
Other & $385(17.1)$ & $63(14.1)$ \\
Board-certified, number (\%) & $1958(86.7)$ & $392(87.3)$ \\
Years in practice, number (\%) & & \\
1-5 & $543(24.0)$ & $203(45.7)$ \\
6-11 & $543(24.0)$ & $145(32.5)$ \\
$12-15$ & $354(15.7)$ & $52(11.7)$ \\
16-20 & $151(6.7)$ & $18(4.0)$ \\
>20 & $669(29.6)$ & $27(6.1)$ \\
Type of practice, number (\%) & & \\
Solo & $762(34.1)$ & $90(20.5)$ \\
Two-person & $273(12.2)$ & $54(12.3)$ \\
$\geq 3$ family practice & $610(27.3)$ & $103(23.5)$ \\
$\geq 3$ multispecialty & $271(12.1)$ & $73(16.6)$ \\
Combination & $129(5.8)$ & $37(8.4)$ \\
Other & $191(8.5)$ & $82(18.7)$ \\
Professional activities: mean \% time (SD) & & \\
Office patient care & $76.7(22.9)$ & $77.5(24.9)$ \\
In-hospital patient care & $11.5(11.3)$ & $8.4(10.3)$ \\
Other patient care & $2.1(8.4)$ & $2.1(10.5)$ \\
Teaching & $3.2(9.5)$ & $4.6(11.0)$ \\
Administration & $3.7(10.8)$ & $3.9(10.9)$ \\
Research & $0.5(3.5)$ & $0.9(6.1)$ \\
Other activities & $1.1(5.9)$ & $1.7(9.1)$ \\
\hline & & \\
\hline & & \\
& &
\end{tabular}


Table 2. Distribution of Reported Average Number of Pap Smears per Month and Average Number of Patients per Month by Gender of Provider

\begin{tabular}{lccccc}
\hline $\begin{array}{l}\text { Average number } \\
\text { of Pap smears } \\
\text { per month }\end{array}$ & $\begin{array}{c}\text { Men } \\
(\mathrm{n}=2261) \\
\%\end{array}$ & $\begin{array}{c}\text { Women } \\
(\mathrm{n}=447) \\
\%\end{array}$ & $\begin{array}{c}\text { Average number } \\
\text { of patient visits } \\
\text { per month }\end{array}$ & $\begin{array}{c}\text { Men } \\
(\mathrm{n}=2259) \\
\%\end{array}$ & $\begin{array}{c}\text { Women } \\
(\mathrm{n}=445) \\
\%\end{array}$ \\
\hline $1-10$ & 20.1 & 12.3 & $1-100$ & 6.7 & 9.9 \\
$11-20$ & 33.8 & 16.6 & $101-200$ & 4.1 & 19.6 \\
$21-30$ & 22.8 & 17.2 & $201-300$ & 24.2 & 19.6 \\
$31-40$ & 11.1 & 18.8 & $301-400$ & 24.4 & 16.2 \\
$41-50$ & 6.9 & 14.1 & $401-500$ & 17.8 & 10.6 \\
51 or more & 4.5 & 21.0 & 501 or more \\
$p<0.00001$ & & & $p<0.00001$ & & \\
\hline
\end{tabular}

Pap smears on average each month $(p<0.00001)$, even after adjusting for part-time status.

Only $10 \%$ of the physicians indicated that they perform a Pap smear at the same interval regardless of the risk of the woman. Response to this question did not differ significantly based on physician characteristics, number of risk factors listed, listing a risk factor that is not evidence supported, number of Pap smears performed per month, or perception of percent of women in practice at increased risk for cervical cancer.

The percent of respondents listing one of the primary risk factors for cervical cancer is and the mean importance score assigned for each risk factor are shown in Table 3. The mean number of risks reported by physicians was $4.5 \pm 1.9$. Physician's age and the number of reported risks were significantly inversely correlated $(p=0.0001)$. Female physicians reported significantly more risk factors than male physicians $(5.3 \pm 1.2$ vs $3.1 \pm$ 1.3, $p=0.05)$. The number of Pap smears performed per month was positively correlated with the number of risk factors reported ( $p \leq 0.001)$. These relationships were the same if the number of risks reported was restricted to primary risk factors. No other physician characteristics were related to risk reported, number of risks reported, or the importance of each risk.

The response category of Other (Table 3) contains identified risks not found to be supported by current medical literature. Of the respondents, 1927 identified 90 other risk factors for cervical cancer. The top 8 other responses were family history of cervical cancer $(905,33 \%)$, age $(316,11 \%)$, in utero diethylstilbestrol exposure (304, 11\%), number of pregnancies $(273,10 \%)$, oral contraceptive use $(251,9 \%)$, uncircumcised male partner $(244,9 \%)$, race $(220,9 \%)$, and low socioeconomic status $(199,7 \%)$.

Physicians' reported perception of the percent of women at increased risk for cervical cancer in their practice ranged from $0 \%$ to $100 \%$, with a mean of $26 \%$. Seventy percent of physicians reported that $20 \%$ or less of their female patients

Table 3. Number and Percent of Responders Identifying Evidence-Supported Risk Factors for Cervical Cancer and Mean Importance Score Given This Risk $(n=2748)$

\begin{tabular}{lccc}
\hline & Number & $\%$ & Mean importance score \\
\hline Multiple partners & 2167 & 79 & 4.2 \\
Early age intercourse & 1440 & 52 & 3.8 \\
Human papillomavirus & 564 & 20 & 4.5 \\
Frequent sexually transmitted disease & 758 & 28 & 3.9 \\
Herpes simplex virus & 848 & 31 & 3.9 \\
Abnormal Pap smear & 497 & 18 & 4.6 \\
Smoking & 564 & 21 & 2.9 \\
Poor screening compliance & 57 & 2 & 4.0 \\
Partner with multiple partners & 55 & 2 & 3.8 \\
Sexually active & 144 & 5 & 3.9 \\
Other & 1927 & 70 & - \\
\hline
\end{tabular}

aThis category contains risk factors identified by physicians but not supported in the medical literature. 
were at increased risk for cervical cancer. Female physicians were significantly more likely than male physicians to report their practice as having a higher percentage of women at increased risk for cervical cancer (31\% vs. $22 \%, p<0.000001$ ).

\section{DISCUSSION}

This sample of family physicians from across the country has a limited understanding of the risk factors for cervical cancer. This was true regardless of the age, training, race, geographic location, practice setting, or the reported risk of their practice population of the responding physician. Female physicians and physicians performing more Pap smears (regardless of gender) on average per month are aware of more of the risk factors but not enough to risk-assess woman for cervical cancer. Numerous risks for cervical cancer were reported that have not been supported or have not been addressed in the published literature.

If risk assessment for cervical cancer is critical to initiating the screening process as well as deciding on the interval at which to screen, 18,19 there are several well-established risks that should be used. The risk factors supported by the medical literature are early age of initiating sexual intercourse, ${ }^{20-22}$ multiple partners ${ }^{20,22-25}$ a sexual partner with multiple partners, ${ }^{23,26-28} \mathrm{hu}$ man papillomavirus, ${ }^{29,30}$ herpes virus, ${ }^{20,31}$ atypia or dysplasia, ${ }^{32,33}$ frequent sexually transmitted diseases, ${ }^{23,26-28}$ smoking of cigarettes, ${ }^{34-41}$ and poor screening compliance. ${ }^{42-44}$ In this sample of family physicians, the number of reported risk factors considered was relatively low, along with many other risks being identified.

Some of the risk factors identified by the respondents that lack published evidence may reflect misunderstanding of risk factors or physicians using their own experience. For example, race and low socioeconomic satus may represent characteristics of women in a physician's practice who initiate sexual intercourse at an early age, have multiple sexual partners, and smoke. Race and low socioeconomic status are not the risk but are easier identifiers on which physicians can focus their attention and screening efforts. In utero diethylstilbestrol exposure places a woman at risk for a clear-cell cervical and vaginal cancer. ${ }^{45,46}$ This risk does not alter the time to initiate or how often to screen for cervical cancer. The risk alters where and how to screen.

Some would question if it is of any importance to know whether family physicians can risk-assess women to reduce the interval of screening. ${ }^{19}$ The current guidelines from the ACS have removed any assessment of risk. ${ }^{16}$ It has been estimated that screening women aged 20-64 every 3 years with a Pap smear reduces the cumulative incidence of invasive cervical cancer by $91 \%$. Annual screening reduces the incidence by $93 \%$, but at a substantial increased cost, use of resources, and patient anxiety. ${ }^{47}$ This has been confirmed with population-based data. ${ }^{48}$ Thus, it would appear that it does not matter whether one screens every year or every 3 years, regardless of the risk of the woman, yet many gynecologists recommend a Pap smear at least once a year. ${ }^{49}$ Even among this study population, only $10 \%$ did not consider risk in establishing a frequency for Pap smear. So the usual practice and opinion of this sample of physicians would suggest that knowledge and use of risk factor are a critical aspect of screening for cervical cancer.

Assessing this information was difficult, as discovered in the pilot phase of the instrument development. In the pilot phase, physicians could easily identify evidence-supported risk factors from a list of possible risks. However, a telephone interview of these physicians did not confirm that the physicians were cognitively fluent with these risk factors. During the telephone interview, many physicians noted they were not sure about the risk factors, but they used their test taking experience to eliminate "false" risk factors and identify "true" risk factors. In an attempt to provide the family physicians with more structure, the question was revised to what the medical literature suggests as many as 10 identifiable risk factors. Even with this approach, the mean number of risk factors listed was only 4.5. In addition, over $70 \%$ of the respondents listed risk factors that have not been supported in the medical literature. The listing of other risk factors may have been driven by the question format, which provided space for 10 answers. This misunderstanding of risk for cervical cancer is not unique to this sample. From a survey of 200 general practitioners in Australia, 50\% of the respondents incorrectly reported they would screen a woman for cervical cancer who had never been sexually active. ${ }^{50}$

The primary limitation to this study is the re- 
liance on self-reported behavior and assessment of knowledge. Physicians in this study may in reality not vary their screening interval for Pap smear on the basis of a woman's risk. Their actual application of cervical cancer risk factor may be more accurate than assessed. However, one would anticipate their responses to overestimate and not underestimate their abilities. The response rate was acceptable, and nonresponders seem very unlikely to differ in knowledge or practices from responders.

Should actions be taken to remedy this knowledge deficit among family physicians? If more family physicians were aware of the risk for cervical cancer, would more women be adequately screened for cervical cancer? This study does not address this issue. Given the low level of knowledge by family physicians and the increasing percent of women adequately screened for cervical cancer, ${ }^{51,52}$ it appears not to be a high priority to address. Promoting the new guidelines for cervical cancer screening may be far more effective at eliminating cervical cancer than any campaign to increase physicians knowledge about risk factors for cervical cancer.

\section{CONCLUSIONS}

The majority of the respondents believe that risks are important in initiating screening and establishing a screening interval. However, their responses suggest that they cannot accurately risk assess women for cervical cancer. This sample of family physicians had very limited knowledge of risk for cervical cancer. If a woman's risk for cervical cancer is critical to the success of cervical cancer screening, further research needs to explore if physicians actually use their risk assessment in making the decision to initiate screening or in establishing a screening interval. The current recommendations for screening for cervical cancer that remove risk assessment are more likely to be implemented and accepted.

\section{ACKNOWLEDGMENTS}

We thank Daniel W. Gorenflo, Ph.D., for management of the data and Kathy E. Carter and Sandi Smith for editorial assistance. We also thank all the physicians who took the time to fill out and return the survey.

\section{REFERENCES}

1. Papanicolaou GN, Traut HF. The diagnostic value of vaginal smears in carcinoma of the uterus. $\mathrm{Am} \mathrm{J} \mathrm{Ob-}$ stet Gynecol 1941;42:193.

2. Ayre JE. Selective cytology smear for diagnosis of cancer. Am J Obstet Gynecol 1947;53:609.

3. Nieburgs HE. A comparative study of different techniques for the diagnosis of cervical carcinoma. Am J Obstet Gynecol 1956;72:511.

4. Nieburgs HE. Review of techniques of cervical smears. Acta Cytol 1960;4:226.

5. HoYuen B, Fidler HK, Boyes DA. In situ carcinoma of the uterine cervix. CMAJ Canadian Medical Journal 1968;99:719.

6. Ruch RM, Blake C, Abou A, Lado M, Ruch WAJ. The changing incidence of cervical carcinoma. $\mathrm{Am} \mathrm{J} \mathrm{Ob-}$ stet Gynecol 1964;89:727.

7. Fidler HK, Boyes DA, Worth AJ. Cervical cancer detection in British Columbia. I Obstet Gynaecol Br Commonw 1968;75:392.

8. Cervical cancer screening programs. IV. Relations between screening programs for carcinoma of the cervix and other screening and preventive programs in Canada. Can Med Assoc J 1976;114:1031.

9. Cervical cancer screening programs. III. Components of a practical screening program for carcinoma of the cervix. Can Med Assoc J 1976;114:1027.

10. Cervical cancer screening programs. II. Screening for carcinoma of the cervix. Can Med Assoc J 1976;114: 1013.

11. Cervical cancer screening programs. V. Conclusions and recommendations of the task force. Can Med Assoc J 1976;114:1033.

12. Dawang Y, Jufang Y, Shoufu X, Yixian L. Mass cytologic screening for cervical carcinoma in China. A review of 7,735,057 reported cases. Acta Cytol 1985;29:341.

13. Smith R, Mettlin C, Davis K, Eyre H. American Cancer Society guidelines for early detection of cancer. CA Cancer J Clin 2000;50:34.

14. Janicek M, Averette H. Cervical cancer: Prevention, diagnosis and therapeutics. CA Cancer J Clin 2001; 51:92.

15. Screening for cervical cancer. In: DiGuiseppi C, Atkins D, Woolf S, eds. Guide to clinical preventive services: Report of the U.S. Preventive Services Task Force. Baltimore: Williams \& WIlkins, 1996:105.

16. Smith R, Cokkinides V, Eyre H. Amercian Cancer Society guidelines for the early detection of cancer, 2003. CA Cancer J Clin 2003;53:27.

17. Dillman D. Mail and telephone surveys: The total design method. New York: John Wiley \& Sons, 1978.

18. Fink DJ. Change in American Cancer Society checkup guidelines for detection of cervical cancer. CA Cancer J Clin 1988;38:127.

19. Frame PS, Frame SJ. Determinants of cancer screening frequency: The example of screening for cervical cancer. J Am Board Fam Pract 1998;11:87.

20. Hulka BS. Risk factors for cervical cancer. I Chronic Dis 1982;35:3. 
21. Rotkin ID. A comparison review of key epidemiological studies in cervical cancer related to current searches for transmissible agents. Cancer Res 1973; 33:1353.

22. Boyd JT, Doll R. A study of the aetiology of carcinoma of the cervix uteri. Br J Cancer 1964;18:419.

23. Rotkin ID. Sexual characteristics of a cervical cancer population. Am J Public Health 1967;57:815.

24. de Vet HCW, Sturmans F. Risk factors for cervical dysplasia: Implications for prevention. Public Health 1994;108:241.

25. Thomas DB, Ray RM, Pardthaisong T, et al. Prostitution, condom use, and invasive squamous cell cervical cancer in Thailand. Am J Epidemiol 1996;143:779.

26. Terris M, Wilson F, Smith H, Sprung E, Nelson JH. The relationship of coitus to carcinoma of the cervix. Am J Public Health 1967;57:840.

27. Harris RWC, Brinton LA, Cowdell RH, et al. Characteristics of women with dysplasia or carcinoma in situ of the cervix uteri. Br J Cancer 1980;42:359.

28. Peters RK, Thomas D, Hagan DG, Mack TM, Henderson BE. Risk factors for invasive cervical cancer among Latinas and non-Latinas in Los Angeles County. J Natl Cancer Inst 1986;77:1063.

29. Schiffman MH, Bauer HM, Hoover RN, et al. Epidemiologic evidence showing that human papillomavirus infection causes most cervical intraepithelial neoplasia. I Natl Cancer Inst 1993;85:958.

30. Schiffman MH. New epidemiology of human papillomavirus infection and cervical neoplasia. I Natl Cancer Inst 1995;87:1345.

31. Winkelstein WJ, Shillitoe EJ, Brand R, Johnson KK. Further comments on cancer of the uterine cervix, smoking, and herpesvirus infection. Am J Epidemiol 1984;119:1.

32. Koss LG, Stewart FW, Foote FW, Jordan MJ, Bader GM, Day E. Some histological aspects of behavior of epidermoid carcinoma in situ and related lesions of the uterine cervix. Cancer 1963;16:1160.

33. Christopherson WM, Gray LAS. Dysplasia and preclinical carcinoma of the uterine cervix: Diagnosis and management. Semin Oncol 1982;9:265.

34. de Vet HC, Sturmans F, Knipschild PG. The role of cigarette smoking in the etiology of cervical dysplasia. Epidemiology 1994;5:631.

35. Clarke EA, Morgan RW, Newman AM. Smoking as a risk factor in cancer of the cervix: Additional evidence from a case-control study. Am J Epidemiol 1982;115: 59.

36. Hellberg D, Valentin J, Nilsson S. Smoking and cervical intraepithelial neoplasia. Acta Obstet Gynecol Scand 1986;65:625.

37. La Vecchia C, Franceschi S, Decarli A, Fasoli M, Gentile A, Tognoni G. Cigarette smoking and the risk of cervical neoplasia. Am J Epidemiol 1986;123:22.

38. Lyon JL, Gardner JW, West DW, Stanish WM, Hebertson RM. Smoking and carcinoma in situ of the uterine cervix. Am J Public Health 1983;73:558.

39. Sasson IM, Haley NJ, Hoffmann D, Wynder EL, Hellberg D, Nilsson S. Cigarette smoking and neoplasia of the uterine cervix: Smoke constituents in cervical mucus. N Engl J Med 1985;312:315.

40. Stellman SD, Austin H, Wynder EL. Cervix cancer and cigarette smoking: A case-control study. Am J Epidemiol 1980;111:383.

41. Trevathan E, Layde P, Webster LA, Adams JB, Benigno $\mathrm{BB}$, Ory $\mathrm{H}$. Cigarette smoking and dysplasia and carcinoma in situ of the uterine cervix. IAMA 1983;250:499.

42. Morell ND, Taylor JR, Snyder RN, Ziel HK, Saltz A, Willie S. False-negative cytology rates in patients in whom invasive cervical cancer subsequently developed. Obstet Gynecol 1982;60:41.

43. Martin PL. How preventable is invasive cervical cancer? A community study of preventable factors. Am J Obstet Gynecol 1972;113:541.

44. Carmichael JA, Jeffrey JF, Steele HD, Ohlke ID. The cytologic history of 245 patients developing invasive cervical carcinoma. Am J Obstet Gynecol 1984;148:685.

45. Anderson B, Watring WG, Edinger DDJ, Small EC, Netland AT, Safaii H. Development of DES-associated clear-cell carcinoma: The importance of regular screening. Obstet Gynecol 1979;53:293.

46. Piver MS, Lele SB, Baker TR, Sandecki A. Cervical and vaginal cancer detection at a regional diethylstilbestrol (DES) screening clinic. Cancer Detect Prev 1988; 11:197.

47. Group IW. Screening for squamous cervical cancer: Duration of low risk after negative results of cervical cytology and its implication for screening policies. IARC Working Group on evaluation of cervical cancer screening programmes. Br Med J Clin Res Ed 1986;293:659.

48. Boon ME, de Graaff Guilloud JC, Rietveld WJ, Wijsman-Grootendorst A. Effect of regular 3-yearly screening on the incidence of cervical smears: The Leiden experience. Cytopathology 1990;1:201.

49. Weisman CS, Celentano DD, Hill MN, Teitelbaum MA. Pap testing: Opinion and practice among young obstetrician-gynecologists. Prev Med 1986;15:342.

50. Bowman JA, Redman S, Reid ALA, Sanson-Fisher RW. General practitioners and the provision of $\mathrm{Pa}$ panicolaou smear-tests: Current practice, knowledge and attitudes. Med J Aust 1990;152:178.

51. Blackman D, Bennett E, Miller D. Trends in self-reported use of mammograms (1989-1997) and Papanicolaou test (1991-1997)—Behavioral risk factor surveillance system. MMWR 1999;48:1.

52. Healthy People 2000 Final Report. Hyattesville, MD: National Center for Health Statistics, 2001.

Address reprint requests to: Mack T. Ruffin IV, M.D., M.P.H. Department of Family Medicine University of Michigan Medical Center Ann Arbor, MI 48109-0708

E-mail: mruffin@umich.edu 